\title{
Results of Wound Healing and Mortality Rate of 156 Consecutive Laparotomies Performed in the Gynæcological Ward of the Glasgow Royal Infirmary During the Year 1909.*
}

\author{
By G. Balfodr Marshall, M.D., F.R.F.P.S.G., \\ Senior Gynacological Surgeon, Glasgow Royal Infirmary; \\ Lxtra Mural Lecturer on Obstetrics and Gynacology.
}

During the year 1909, 266 operations were performed under anasthesia, and of this number 156 were laparatomies. The ward accommodation is at present too limited to overtake all the material placed at our disposal, and the amount of work recorded is only possible by dismissing patients as soon as they are fit to go home. Thus the large majority of the laparotomies leave hospital on the 16 th day after operation.

Inflammatory diseases of the uterine adnexa are very common and no less than 65 of the laparotomy cases, equal to a percentage of $41 \cdot 6$, suffered from chronic salpingitis or pyosalpinx. Although many of them were gonorrhcal or tubercular in origin yet it is astonishing what a large proportion dated from the puerperium as the result of septic infection in midwifery practice.

The deaths were six, giving a percentage mortality of 3.9 . Two of the 6 cases were so ill that operation might have been refused had there been any desire to keep down the mortality rate, but as it was their only chance there was no hesitation in giving these patients the possible benefit of surgical interference. The third patient died from faulty after-treatment, the house surgeon withdrawing the whole of the pelvic gauze packing 48 hours after operation. The rectum had been injured during a difficult panhystero-salpingo-oöphorectomy and the removal all at once of 6 yards of gauze led to a breakdown of the protecting adhesions with consequent general bacillus coli peritonitis. The other three cases were unexpected deaths, the first on the 17th day after operation from sudden syncope of unknown cause, the pulse and temperature being normal; the second from exhaustion on 14th day due to diarrhoea; the third from ileus on 5th day after an incomplete operation owing to the bowels being universally adherent.

In giving an analysis of the 156 laparotomies, only the indica-

- Read at a meeting of the Glasgow Obstetrical and Gynæcological Society, March 23, 1910. 
tions for operation and the operations required are tabulated, as the main scope of this paper is to give a statement of the technique adopted, and the results obtained both as regards wound healing and mortality.

All surgeons aim at an ideal which will give perfect results and each has his own method for attaining it, but it is not to be looked for by seeing how quickly a patient can be got off the table, an assistant meantime standing by to give the time to the fifth of a second. No surgeon should operate to the gallery. An ovariotomy, for instance, cannot be completed from start to finish within ten or fifteen minutes if the procedures $I$ advocate in opening and closing the abdomen and the thorough peritonisation of all raw surfaces are carefully carried out. Speed is no doubt an important factor and in some cases so vital that certain otherwise important details must be neglected, but it may be and is frequently overdone to the sacrifice of the patient's future well-being, which with a low operative mortality and uninterrupted convalescence is after all the ideal to be attained. What is the use of rapid operating, when not absolutely necessary but solely in the endeavour to beat records, if the patient afterwards suffer constant pain from the use of mass ligatures, especially where silk sutures are employed, or from adhesions caused by surfaces left bare or imperfectly covered with peritoneum, not to mention other risks? Again witness the annoyance and discomfort to a patient who suffers from a ventral hernia resulting from the weak scar following a simple approximation by through and through sutures of an abdominal incision in the linea alba.

Table of Diseases in 156 Consecutive Laparatomies. Uterus.

$\begin{array}{llllllllllll}\text { Prolapse } & \ldots & \ldots & \ldots & \ldots & \ldots & \ldots & \ldots & \ldots & \ldots & \ldots & 6\end{array}$

$\begin{array}{llllllllll}\text { Mobile Retroflexion } & \ldots & \ldots & \ldots & \ldots & \ldots & \ldots & \ldots & \ldots & 33\end{array}$

Fixed Retroflexion all associated with chronic salpin$\begin{array}{lllllllll}\text { gitis or pyosalpinx } & \ldots & \ldots & \ldots & \ldots & \ldots & \ldots & \ldots & 13\end{array}$

$\begin{array}{llllllllllll}\text { Fibromyomata } & \ldots & \ldots & \ldots & \ldots & \ldots & \ldots & \ldots & \ldots & \ldots & 12\end{array}$

$\begin{array}{lllllllllll}\text { Fibrosis uteri } & \ldots & \ldots & \ldots & \ldots & \ldots & \ldots & \ldots & \ldots & \ldots & 1\end{array}$

Carcinoma cervicis (epithelioma 2, adeno-carcinoma 1) 3

$\begin{array}{lllllllll}\text { Adeno-carcinoma corporis } \ldots & \ldots & \ldots & \ldots & \ldots & \ldots & \ldots & \ldots & 1\end{array}$

$\begin{array}{lllllllll}\text { Chorionepithelioma corporis } & \ldots & \ldots & \ldots & \ldots & \ldots & \ldots & 1\end{array}$

Fallopian Tubes.

Tubal gestation (hæmatocele 7 , free hæmorrhage 1,

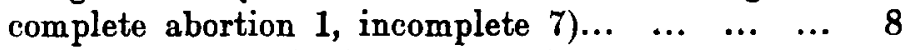

$\begin{array}{llllll}\text { Chronic salpingo-oöphoritis (tubercular } 3) & \ldots & \ldots & \ldots & 36\end{array}$

Pyosalpinx (tubercular 4, tubo-ovarian abscess 3) $\ldots 24$

$\begin{array}{lllllllllll}\text { Hydrosalpinx } & \ldots & \ldots & \ldots & \ldots & \ldots & \ldots & \ldots & \ldots & \ldots & 5\end{array}$ 
Ovaries.

$\begin{array}{llllllllllll}\text { Abscess } & \ldots & \ldots & \ldots & \ldots & \ldots & \ldots & \ldots & \ldots & \ldots & \ldots & 1\end{array}$

$\begin{array}{llllllllllll}\text { Follicular cysts } & \ldots & \ldots & \ldots & \ldots & \ldots & \ldots & \ldots & \ldots & \ldots & 6\end{array}$

Cystoma (unilateral 11, bilateral 7) $\ldots \begin{array}{lllll} & \ldots & \ldots & \ldots & 18\end{array}$

$\begin{array}{llllllllll}\text { Adeno-carcinoma } & \ldots & \ldots & \ldots & \ldots & \ldots & \ldots & \ldots & \ldots & 2\end{array}$

$\begin{array}{llllllllllll}\text { Sarcoma } & \ldots & \ldots & \ldots & \ldots & \ldots & \ldots & \ldots & \ldots & \ldots & \ldots & 1\end{array}$

Broad Ligament.

$\begin{array}{llllllllllll}\text { Varicocele } & \ldots & \ldots & \ldots & \ldots & \ldots & \ldots & \ldots & \ldots & \ldots & \ldots & 3\end{array}$

$\begin{array}{llllllllllll}\text { Cystoma } & \ldots & \ldots & \ldots & \ldots & \ldots & \ldots & \ldots & \ldots & \ldots & \ldots & 2\end{array}$

Peritoneum.

Suppurative peritonitis (tubercular 1, ruptured ovarian

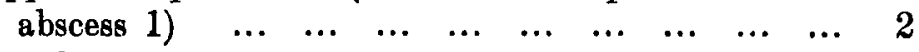

$\begin{array}{llllllllll}\text { Lympho-sarcoma } & \ldots & \ldots & \ldots & \ldots & \ldots & \ldots & \ldots & \ldots & 1\end{array}$

Various.

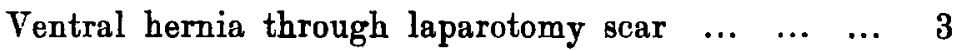

$\begin{array}{llllllllll}\text { Umbilical hernia } & \ldots & \ldots & \ldots & \ldots & \ldots & \ldots & \ldots & \ldots & 1\end{array}$

$\begin{array}{lllllllllll}\text { Cyst of urachus } \ldots & \ldots & \ldots & \ldots & \ldots & \ldots & \ldots & \ldots & \ldots & 1\end{array}$

$\begin{array}{lllllllllll}\text { Appendicitis } & \ldots & \ldots & \ldots & \ldots & \ldots & \ldots & \ldots & \ldots & \ldots & 6\end{array}$

Many of the above were associated with other conditions as complications which required an extension of the operation.

Table of Operations in 156 Laparotomies.

1. Prolapsus uteri :

(a) Round ligament suspension and colpoperineo$\begin{array}{lllllllllll}\text { plasty } & \ldots & \ldots & \ldots & \ldots & \ldots & \ldots & \ldots & \ldots & \ldots & 5\end{array}$

(b) Ventro-fixation, colpoperineoplasty and sal$\begin{array}{llllllll}\text { pingo-oöphorectomy } & \ldots & \ldots & \ldots & \ldots & \ldots & \ldots & 1\end{array}$

2. Retroflexio uteri (mobile) :

(a) Round ligament suspension, combined with colpoperineoplasty 4, amputation and repair of cervix 2 , unilateral oöphorectomy 2 , ovariotomy 1 , excision of varicocele $1 \ldots \ldots$...

(b) Ventrosuspension, combined with colpoperineoplasty 1 , salpingo-oöphorectomy $1 \ldots \ldots \ldots$

3. Retroflexio fixata :

(a) Round ligament suspension, combined with conservative operations on adnexa... $\ldots \ldots \ldots$

(b) Ventro-fixation, combined with removal of tubes

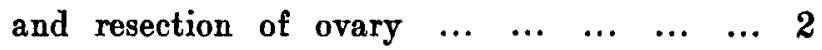

4. Fibromyomata uteri :

(a) Myomectomy on pregnant uterus $\ldots \begin{array}{llll} & \ldots & \ldots & \end{array}$

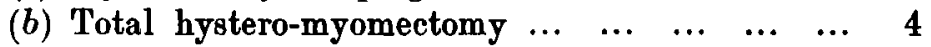

(c) Subtotal ", $\quad, \quad \begin{array}{llllllll} & \ldots & \ldots & \ldots & \ldots & \ldots & 7\end{array}$

Combined with appendicectomy 1, enucleation of parovarian cyst 1 . 


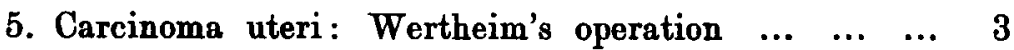

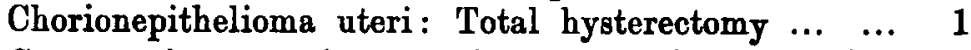

6. Conservative operations on adnexa, resection of ovaries, $\begin{array}{lllllllll}\text { releasing adhesions } & \ldots & \ldots & \ldots & \ldots & \ldots & \ldots & \ldots & 5\end{array}$

i. Salpingectomy for tubal gestation...

8. Unilateral salpingo-oöphorectomy (pyosalpinx 1, chronic salpingo-oöphoritis 17), combined with appendicectomy 2 , ovariotomy for cystoma 1 , round $\begin{array}{lllllllll}\text { ligament suspension } & 5 \ldots & \ldots & \ldots & \ldots & \ldots & \ldots & \ldots & 18\end{array}$

9. Bilateral salpingo-oöphorectomy (pyosalpinx 11, salpingo-oöphoritis 9), combined with appendicectomy $2 \quad 20$

10. Bilateral salpingectomy with resection of ovaries $\ldots 6$

11. Panhystero-salpingo-oöphorectomy for bilateral pyosalpinx, combined with resection of bowel 1 , appendi-

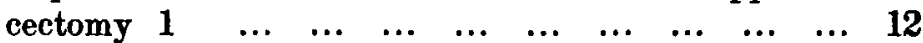

12. Unilateral oöphorectomy for follicular cysts $\ldots$...

13. Ovariotomy bilateral 7 , unilateral 11 ..

14. Venectomy for varicocele broad ligament; other com$\begin{array}{llllllllllll}\text { plications... } & \ldots & \ldots & \ldots & \ldots & \ldots & \ldots & \ldots & \ldots & \ldots & 3\end{array}$

15. Laparotomy for tubercular peritonitis...





18. Exploratory laparotomy for constant fixed pain... $\quad \ldots \quad 2$

19. Resection of ileum owing to densely adherent pyosal$\begin{array}{lllllllllllll}\operatorname{pinx} \ldots & \ldots & \ldots & \ldots & \ldots & \ldots & \ldots & \ldots & \ldots & \ldots & \ldots & 1\end{array}$

20. Appendicectomy combined with other operations $\ldots$... 6

21. Vaginal hysterectomy for fibrosis uteri... $\ldots$...

\section{Mortaltry.}

6 deaths $=3.9 \%$

\section{Nature of Case and Cause of Drath.}

1. Hystero-myomectomy : constant uncontrollable diarrhcea, death from exhaustion 14th day.

2. Hysterectomy for chorionepithelioma : large sloughing tumour; patient very ill; post operative septic peritonitis, death 63 hours.

3. Panhystero-salpingo-oöphorectomy for pyosalpinx: rectum injured. Well till all pelvic gauze packing removed contrary to orders on 3rd day. B. coli peritonitis followed. Death 6 th day.

4. Tubercular peritonitis: universal intestinal adhesions, incomplete operation; death from ileus 5 th day.

5. Suppurative peritonitis: well till 17th day, death in 10 minutes from sudden syncope, cause unknown as no post mortem permitted. 
6. Hystero-myomectomy for sloughing fibroid and suppurative peritonitis: lower abdomen full of pus. Did not rally after operation. Death in 2 hours from shock.

\section{General Technique.}

Preparatory Treatment. Except in cases of emergency patients are kept at least three days in bed before laparotomy, but if debilitated or anæmic, sufficiently long to improve greatly their condition, since feeble women have little resisting power to infection and are more liable to post-operative shock. In cases of anæmia due to prolonged hæmorrhage as from fibroids, a blood count is taken at regular intervals to judge of the fitness of a patient for hysterectomy.

Patients before being put to bed are bathed and the head thoroughly cleansed. The vulva and mons veneris even for minor operations are shaved and all patients are antiseptically douched twice daily.

The food should be simple but ample and fluids partaken of freely to flush the kidneys. I do not believe in purging patients before operation. A full dose of castor oil, the best of all laxatives for gently but thoroughly emptying the bowels, is given on admission and repeated as required to ensure daily evacuation. On the morning of operation the lower bowel is washed out with a large simple enema. I prescribe Bismuth Subnitrate gr. xx with Salol gr. $\mathbf{v}$ thrice daily before food for the three days preceding operation, as $I$ find this largely prevents the flatulent distension of the small intestine, which when present is so troublesome to the operator and difficult to pack back out of the pelvis.

Preparation of abdomen. My former practice was to have the skin cleansed with turpentine and ether 48 hours before operation and covered by a sterile dressing. This was replaced about 4 hours prior to operation by a carbolic dressing which was only removed for the final disinfection after the patient was on the table. This gave very good results, $88 \%$ of the abdominal wounds healing perfectly, as will be shown further on. I had doubts if this prolonged preliminary preparation of the field of operation was really necessary if not perhaps a disadvantage, as the moist dressing poulticed and rendered the skin sodden. Wounds did quite as well where as in emergency cases the cleansing was done just before operation. There was the further disadvantage that nervous women were much upset by the procedure. Since the beginning of this year I have simplified the procedure with results which so far leave little to be desired judging by a series of over 100 cases. The patient gets a bath the night before and no covering is placed on the abdomen. She has already been shaved on admission to hospital. While the patient is being anæsthetised the whole abdomen is 
thoroughly scrubbed with ethereal soap solution and sterile water, using a sterile brush.. This is followed by a thorough swabbing with 1 in 500 methylated spirit mereuric biniodide and not more than 4 or 5 minutes are spent in the process. The results have been so good that there has been no special inducement to abandon this method for iodine. Sterilized towels completely cover the patient and are fastened to the skin round the field of operation by towel clips, leaving just sufficient room for the incision and subsequent manipulation. The skin is thus completely covered up to the edges of the incision so that the gloved hands do not come in contact with it. Fresh towels are placed round the field of operation before the final closing of the abdomen or earlier if soiled as from the contents of an ovarian cystoma.

Operator and assistants. The fewer assistants the better. Operator and assistant remove outdoor clothing, put on operating suits and canvas shoes, and wear sterile gown, sleeves, and rubber gloves. The head and face are completely covered up with a cap and face piece which is tucked under the gown in front. The opening in the face piece is just large enough to see through.

Only one nurse is required to manage the instruments and thread needles, and she also wears cap, gown, and rubber gloves. A second nurse frequently changes the sterile water in which the gloved hands are cleansed during operation.

No sponges are used, only sterilized gauze swabs, which are tied up in bundles of one dozen, from 1 to 3 dozen swabs sufficing for most operations. They are handled solely by the assistant, who drops them after use into a special pail, and is responsible for the number. Every swab must be accounted for before the abdomen is closed, a precaution which is absolutely necessary.

The hands are cleansed under running water with ethereal soap solution and brush for about 5 minutes, longer is not necessary, and then thoroughly swabbed for other 4 or 5 minutes in 1 in 500 mercuric biniodide spirit solution. I put on the rubber gloves with the hands wet from this lotion.

The rubber gloves are śterilized by boiling and are put on wet from sterile water. Boiling injures them less than dry sterilization so that they last a little longer.

They are easily and snugly applied by filling each glove with water and using a piece of sterile gauze to draw on the fingers. The use of the gauze has the further advantage of preventing the gloves being handled by the skin while being drawn on. Some surgeons still see fit to sneer at gloves, but of this I am absolutely convinced, that since using them the percentage of perfectly healed wounds is higher both as regards laparotomies and colporrhaphies, and there is no risk of infecting the catgut, which I use exclusively for all suturing except skin and bowel. One soon becomes accus- 
tomed to the use of gloves so that there seems to be no loss of tactile sense. A glove can be absolutely sterilized and, if soiled during operation, changed for another. This is impossible with the skin, and if the hand be infected during operation by pus or fæcal matter, much valuable time is lost in recleansing, whereas the changing of gloves is a matter of a few seconds.

Instruments. All instruments are sterilized by boiling and laid on sterilized lint in a tray. Those required for suturing the abdominal wound are kept apart, enclosed in sterilized lint on a separate tray, and are not touched or exposed till needed.

The knife which cuts the skin is laid aside and a fresh knife taken to cut the deeper layers. The artery forceps used for the subcuticular vessels are reboiled after removal.

Instruments which have been in contact with pus tubes or other infected areas and those used for intestinal work are laid aside, or if likely to be required again are resterilized.

Method of opening and closing the abdomen. The skin and fat are incised in the linea alba to the fascia and then on the left side dissected off the sheath of the left rectus to a distance sufficient to allow of opening the sheath about $\frac{1}{4}$ inch from the inner border of the muscle and leave a wide enough margin free of fat for subsequent suture. The muscle is dissected, not torn, from its attachments to the sheath and turned outwards, the peritoneum being finally opened to the left of the middle line so that when closed again the line of suture is covered and supported by muscle.

I have tried many ways of closing the abdomen but now suture in four layers by the following method, which leaves nothing to be desired, since the scar is perfect forming a fine line; there is no weakness, every suture line being supported by the overlapping layers; an abdominal belt for future support is not necessary, nor do I over prescribe one, and so far no patient has reported herself with a ventral hernia. Yet I have seen many hernia following through and through suturing in one layer, a method I never adopt unless compelled to by special pircumstances demanding speed such as shock on the table or where the patient is already in a feeble condition, and even then I prefer to first close the peritoneum with a continuous catgut suture.

The peritoneum is closed by a continuous suture of No. 220 -day chromicised catgut threaded on a round needle, special care being taken to include the transversalis fascia and aponeurosis which by retracting are liable to be overlooked. The rectus muscle is brought into position over this and sutured into place by No. 2 catgut mattress or continuous suture, and for the latter the peritoneal needle and suture may be utilised if left long enough to complete both layers. A needle with cutting edge should not be used for the muscle as it causes hæmorrhage. 
The sheath of the rectus is now closed by a continuous No. 3 catgut and a stronger line of union is obtained if the edges are made to overlap. This is done by taking an in and out bite of the left side as with a Lembert suture, the needle being then passed from behind through the right side so that when the suture is pulled taut the right edge overlaps the left, ensuring a strong scar. The skin and fat being united in the middle line completely overlap and support this.

For closing the skin and fat layer silkworm gut sutures are used, interrupted if wall be thick, continuous if thin, and sometimes a combination of both methods. The needle should enter and emerge close to the skin edge, since if a big bite be taken there is very apt to be an inturning or overlapping of skin edge interfering with perfect union. Special care must be taken to include the underlying fascia with the skin sutures to avoid leaving dead spaces in which blood or serum may collect. Care must also be taken to tie the sutures only sufficiently tightly to approximate gently the wound surfaces. Sutures tied too tightly interfere with perfect union.

The wound is freely swabbed with hot saline as each layer is completed. When the wound is finally closed the skin surface is washed, cleaned, dried, and covered with dry sterile dressings, kept in place by a flannel binder. No antiseptic dusting powders are used, nor are they necessary. The skin stitches are removed on the 10th day and the scar covered by a piece of gauze fixed in position by strips of plaster.

Two cases operated on last year, during the 6th week of pregnancy, both went to term without any injury to the scar, yet no supporting belt was worn and no hernia has appeared.

The catgut I use is van Horn's and, to my knowledge in many hundreds of operations, I have never found it fail me as regards sterility. Catgut has been and is too often blamed for a wound going wrong, when it is more likely some fault in technique, and I have noted many ways in which catgut or wound may be infected, some of which should be mentioned. While investigating some unaccountable cases of sepsis amongst my ward patients I learnt that the instrument nurse, although wearing rubber gloves and cap, put her fingers to her hair and adjusted her eyeglasses during the course of the operation, no doubt unconsciously, and until I discovered the cause blamed the catgut, although pieces sent to the bacteriologist were declared quite sterile. A change of nurse reduced my cases of sepsis to a very large extent. A catgut ligature may be allowed to trail against blanket, table, or basin, or a forgetful instrument nurse may even suck the end of the ligature on experiencing difficulty in threading it.

$I$ have seen operators without protecting masks talking freely 
while bent over the open abdomen and have noticed the brow perspiration drop on to peritoneum and wound. While watching a surgeon I noticed the nurse, who was responsible for his gauze swabs and who stood behind him, give him one with the same fingers with which she had just been arranging stray locks in her hair. This piece of gauze was used to wipe peritoneum.

To avoid such risks the gauze swabs are placed where I can see them beside the assistant and he alone handles them. The instrument nurse also stands where her every movement can be noticed.

Results of wound healing. The following are the results in 152 of the laparatomies, the other four having died before the stitches were removed.

Healed perfectly by first intention throughout $134=88$ per cent.



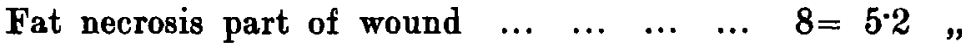

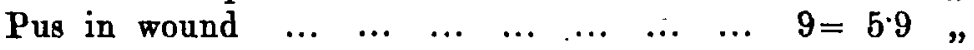

Hamatoma. One case, following Gilliam's round ligament suspension of the uterus. This is prone to occur after ventrosuspension, but this is the only instance in which $I$ have seen it after round ligament suspension in an experience of over 80 cases. The hæmatoma was small and limited to lower end of wound.

Fat necrosis is that condition where the wound apparently heals by first intention owing to the skin edges uniting, but a small opening appears later in the scar through which a thin bloodtinged serous fluid escapes. It is associated with a slight rise in pulse rate and temperature. The fluid may escape by the end of the first week or not till the stitches are removed on 10th day. In one case it did not show till the 13th day and 3 days after the stitches had been removed. It is limited to the deeper fat layer and is favoured if any dead spaces are left. All that is necessary for treatment is to enlarge the small opening sufficiently to admit a small wick drain. The sinus closes rapidly as a rule without any further yielding of skin and does not weaken the scar.

Suppuration of the wound. If the wound be infected and pus form the result is very different. The whole skin and fat layer gape, in some cases even the fascia and muscle, the surfaces being covered by sloughs. Such a wound takes a long time to fill up by granulations.

Suppuration occurred in 9 cases and all after the following severe operations:

$\begin{array}{lllll}\text { Wertheim's operation for cancer of cervix } & \ldots & \ldots & \ldots & 2\end{array}$

Panhystero-salpingo-oöphorectomy for bilateral pyosalpinx in two of which the rectum was torn $\ldots 6$

Bilateral salpingo-oöphorectomy for double pyosalpinx 1 In the last case suppuration being slight the wound was thoroughly cleansed and swabbed with benzine and resutured when it healed 
by first intention. This was tried in one of the others but failed. I have had successes in other cases by waiting till healthy granulations have formed and all sloughs disappeared.

In the two cases in which the rectum was torn the infection was due to the $B$. coli no doubt carried by my fingers before the wounds were discovered and the gloves changed.

In three eases the lower half of the wound only was affected.

Technique inside the abdomen in pelvic operations. The abdomen having been opened and explored by the hand to confirm the diagnosis and note any other possible complications be it in vermiform appendix, or gall bladder, a large two-layer-thick lint pad wrung out of hot saline is inserted and the patient placed in Trendelenberg's position. This lint pad measuring about $9 \times 6$ in., is large enough to cover the intestines completely, and is used to pack them back out of the pelvis, being much superior to gauze for this purpose. The use of such a pad, which not only protects the bowels but keeps them warm and moist, is one of the most important factors in limiting shock and in favouring the comfort of the patient during the first few days after operation. It also so completely shuts off the abdomen above that it diminishes the risk of pieces of gauze used for further protection from slipping upward and being lost. It is a matter of no little difficulty finding a gauze swab which has disappeared amongst coils of intestine.

Clamps are freely used to facilitate speedy removal of organs, for the less dragging there is on retro-peritoneal structures the less shock there is to the patient. The cut vessels by being exposed in the bite of the clamps are easily seen and ligated in their continuity. Mass ligatures are never employed. I consider it bad surgery to bunch up a pyosalpinx, tie the top of the broad ligament with an interlacing suture and then cut it through like the pedicle of a cystoma. Such a procedure is responsible not only for the production of adhesions but for much after pain which may be as bad as, or worse than, that caused by the disease for which the operation was done. I have seen too many of these women, in whom I know mass ligatures were employed in the manner referred to, complaining of distressing pain which nothing short of another operation could relieve. Even for ovarian tumours I do not mass ligature the pedicle but tie the ovarian vessels on each side and cut the pedicle close to the broad ligament, the peritoneum being sutured over the resulting wound.

Where necessary for further security as when the broad ligaments are thick and odematous supplementary ligatures are passed just before closing the abdomen.

I abandoned silk for catgut inside the abdomen in pelvic work over 12 years ago and cannot understand why some surgeons still use it. For a time I tried catgut prepared by the iodine method, 
but now only employ 20 day chromicised catgut except for intestinal work for which No. 1 or 2 celluloid thread is used.

The ligatures for suturing blood vessels are of No. 3, passed double if greater strength is required rather than use a thicker strand. Peritonisation is done with No. 2 threaded on a fine round needle.

I have never had a case of post-operative hæmorrhage with catgut. I lay great stress on the careful peritonisation of all raw surfaces as well as the avoidance of exposing or injuring peritoneum and exposure or handling of intestine. These precautions do more to prevent the formation of post-operative adhesions than any experimental methods tried such as the injection into the abdominal cavity of saline; smearing stumps and raw surfaces with collodion, olive oil, lanolin, fat, or mucilage; or oral administration of phosphorus or peptone.

Different methods of operating do not come within the scope of this paper.

Drainage. Drainage may be necessary after certain operations but the greater the experience of the operator and the more thorough his technique the less often will he drain. For example the separation and removal of a widely adherent bilateral pyosalpinx may leave such extensive raw oozing surfaces that drainage is required, when this could be avoided by the more thorough and better operation of hystero-salpingo-oöphorectomy after which it is possible to cover in all raw surfaces with peritoneum. Drainage is not necessary if the pus from a pyosalpinx be sterile so that if some escape simple swabbing will suffice. In any case the peritoneum and surrounding parts should be protected by packing the field of operation well off with gauze which catches any pus which may escape.

Drainage is absolutely contraindicated if an operation be conducted aseptically, all bleeding points controlled and thorough peritonisation of raw surfaces carried out, all three procedures, in addition to those previously mentioned, being most essential factors not only to the success of an operation but also to the future well-being of the patient in the prevention of adhesions.

Drainage may be necessary for the following conditions in all of which I have employed it with advantage to the patient.

(1) Where after separation of numerous adhesions in removing densely adherent ovaries, or ovarian tumours, pus tubes, retroflected uteri, or densely adberent sac of an old hæmatocele there is considerable oozing, which cannot otherwise be controlled or where it is better to pack in gauze for a speedy termination of the operation owing to the critical condition of the patient rather than waste time applying numerous ligatures in a difficult situation; 
(2) Where it is impossible with safety to remove all of a densely adherent cystoma, hæmatocele sac or pus sac;

(3) Where foetid pus has escaped from a pus tube, sac, or ovarian abscess, or where hæmatocele blood clot is septic. Two or three of my cases of tubal abortion and hæmatocele have been complicated with a pyosalpinx in the opposite tube. In one the patient had an acute gonorrhcea with pus in both tubes, and the blood clot which filled the pelvis was stinking yet she made a good recovery.

(4) Where suppurative peritonitis is a complication;

(5) Where the rectum has been torn, an accident which in spite of all care may occur while separating a densely adherent pyosalpinx or tumour;

(6) Where doubt exists as to the integrity of ureter or bladder as after Wertheim's operation for cancer of the cervix or after enucleation of a deeply burrowing fibroid or cyst in the broad ligament.

I do not resort to simple drainage by rubber tube or strips of gauze but pack freely using plain roller gauze of various widths four ply thick, and if necessary fill the pelvis up to the brim, which may require anything up to six or even more yards.

For all pelvic conditions the abdomen is closed and drainage effected per vaginam. For conditions above the pelvis abdominal drainage is of course necessary. If in the enucleation of a broad ligament tumour a large cavity is left which oozes and cannot be effectually closed, thus leading to risk of a hæmatoma forming, I pack the cavity with gauze taken out through an opening made into the vagina and suture the peritoneum over it, thus entirely shutting off the abdominal cavity.

It is sometimes unexpectedly found necessary to drain when the vagina has not been previously disinfected. Several years ago I adopted a plan which does away with what I consider a great risk, viz., hasty cleansing of the vagina by an assistant who pushes a pair of forceps against the posterior fornix on which the operator euts, the same forceps being used to pull down the gauze into the vagina. Sepsis may easily be introduced by this method and there are also other serious risks which should be mentioned as they have actually occurred. An assistant passed the forceps through the urethra, and forced the base of the bladder against the posterior fornix with the result that the bladder was opened. In another unrecorded case the assistant entered the rectum with the forceps upon which the operator cut and the gauze was pulled through the anus.

To pass the forceps under guidance of sight means disturbing the field of operation too much by turning up the sterile covering 
from the legs, and this is doubly disadvantageous when the patient is in Trendelenberg's position.

The plan I adopt is to pack the pelvis as required, close the abdomen and apply the dressings. The patient is then put in the lithotomy position, the vagina thoroughly disinfected,a speculum passed and an incision made with scissors through the posterior fornix directly on to gauze, a piece of which is pulled into the vagina. The vagina should be further packed with gauze from below to check any oozing from the vaginal wound.

This procedure may not be original, although I have not seen it mentioned, but it works admirably, is quickly done, and avoids all the risks already mentioned.

The gauze used for pelvic packing should be left undisturbed till the third day when several inches are pulled down and cut off. After this withdrawal is easy and almost painless to the patient. Each day a further portion is removed until it is finally all withdrawn between the 5th and 7 th day depending on the number of yards used. The vaginal wound should be kept open by a strip of gauze or a tube for several days longer, otherwise it closes too soon and secretion is retained leading to a rise of temperature.

This gradual removal of the gauze is a very necessary precaution, regarding which a young assistant should be carefully instructed. One of the unexpected deaths last year was due to the house surgeon removing the whole of 6 yards of packing 48 hours after operation. The case was one of complete removal of uterus and adnexa for very adherent bilateral pyosalpinx during which the rectum was torn. The sudden removal of so much gauze left a large cavity into which the bowel was forced, breaking down the recent protecting adhesions, with the result that the patient died three days later of B. coli general peritonitis.

Simple drainage with a rubber cigarette drain or rubber tube surrounded by gauze after injury to the rectum is useless. The pelvis should be packed with gauze well above the seat of injury to shut it off completely from the abdominal eavity, and the gauze left undisturbed till the third or fourth day to give time for strong adhesions to form. The last piece of gauze should not be finally withdrawn till about the 7 th day. I have never lost a case after injury to the rectum by this method, and I do not include above case for reason given. You may suture the tear in the rectum, as is proper, but the surrounding parts are certainly infected with the B. coli and fæces may eventually escape per vaginam, but the resulting fistula has always closed in my cases.

Dr. Munro Kerr's suggestion," owing to his bad results after injury to the rectum, to paralyse the sphincter and drain by the

- Trans. Edinb. Obst. Soc., 1908-9, Vol, xxxiv, p. 213. 
anus is a procedure of which I fail to see the rationale, far less appreciate. Accidental drainage through the anus, already referred to, has been grievous in its results.

After treatment. After a straightforward laparotomy with perfect asepsis there is little difficulty about after-treatment. The patient is well from the time she recovers from the ansesthetic and post-operative sickness. In other cases everything depends on skilful management if the patient's life is to be saved.

When required by the state of the pulse strychnine gr. $1 /$ so is given hypodermically every two, four or six hours. I have tried infundibular extract but still prefer strychnine, which is more lasting in its effects.

Morphia I very. rarely use as it interferes with the opening of the howels on the second day. If the patient be very restless and suffering much pain she is the better of it, but I give no more than gr. $\frac{1}{6}$ to $\frac{1}{4}$ and not later than twelve hours after operation.

As a routine treatment during the first 24 hours the patient gets normal saline solution per rectum either by enemata ur proctoclysis. Proctoclysis is specially employed for patients who require to be placed in Fowler's position.

The bowels are moved on the second day as this avoids the discomfort and colicy pain due to flatulence. Within 24 hours of operation three to five grains of calomel are given by mouth followed in three or four hours by teaspoonful doses of magnesium sulphate repeated hourly till from three to five doses are given. If this be not effective a turpentine enema is administered about two hours after the last dose of magnesium sulphate has been given. If the result is not all that is desired half an ounce of caster oil is given on the evening of the second day or morning of third day.

As soon as the stomach will tolerate fluids the patient gets them even on the first day if there be no sickness.

At one time $I$ filled the abdomen with saline as a routine practice and with perfectly good results, but now I rarely employ it preferring proctoclysis, which I regard as one of the most valuable additions to our after-treatment of abdominal operations. In certain cases it is indispensable, and many patients owe their recovery to its employment. I have had patients absorb from five to nine pints in 24 hours.

To be effective the apparatus for proctoclysis must be properly used by an intelligent and painstaking nurse otherwise the patient will not retain the saline. There are, however, patients who seem quite incapable of tolerating proctoclysis, although the chief reason for the failures in getting the saline retained complained of by some is fault on the part of the nurse, and $I$ cannot do better than advise perusal of an excellent paper on the subject by Murphy in "Surgery, Gynæcology and Obstetrics," June 1908, vol. vi, p. 593. 
At first I used a flask and the rectal tube recommended by Moynihan, which worked exceedingly well, although constant attention was necessary to keep the temperature of the saline from falling too low. This is obviated by the Magnuson-Murphy apparatus which I have had in regular use since it was brought to my notice early this year.

With the object of diminishing post-anæsthetic romiting a hypodermic injection of picrotoxin was tried in about 150 consecutive cases, the injection being given before the patient left the operating table. I cannot say there was any noticeable benefit so I discontinued the practice. The best prophylactics are careful preparation of the patient and skilful administration of the anæsthetic.

I am no believer in the latest fashion of getting laparotomised patients out of bed in the first day or two. Patients who do well sit up on the 12th day, rise on the 14th and leave hospital on the 16th day, and this applies to nearly all cases which have not required drainage. 